\title{
Análise do clima urbano de Cuiabá-MT-Brasil por meio de transectos móveis
}

\author{
SANTOS, Flávia Maria de Moura \\ OLIVEIRA, Angela Santana de ${ }^{1}$ \\ NOGUEIRA, Marta Cristina de Jesus Albuquerque \\ MUSIS, Carlo Ralph De \\ NOGUEIRA, José de Souza \\ ${ }^{1}$ Instituto Federal de Educação, Ciência e Tecnologia de Mato Grosso (IFMT), Cuiabá, Brasil. angela.oliveira@cba.ifmt.edu.br
}

\section{Resumo}

As características urbanas associadas aos tipos e graus de adensamento e uso que recobrem o solo têm a capacidade de modificar os elementos climáticos que compõem a atmosfera local. Desta forma, esta pesquisa teve como objetivo analisar a influência da ocupação do solo no microclima em Cuiabá-MT-Brasil por meio das diferenças de temperatura e umidade do ar intraurbana do município. Para tanto, foi usada a metodologia de transectos móveis noturnos nas quatros estações do ano, utilizando-se um termohigrômetro digital, protegido por abrigo, acoplado na lateral de um veículo que saiu da periferia rural, passou pelo centro e chegou ao extremo oposto da cidade, no sentido leste/oeste e posteriormente norte/sul. Foi feita a análise termo-higrométrica e detecção de anomalias climáticas como ilha de calor, evidenciando a influência das mudanças antropogênicas no ambiente urbano. O adensamento urbano e a supressão de vegetação são fatores determinantes na modificação do comportamento termo-higrométrico, sendo evidente a influência do fluxo de veículos automotores nos ganhos de calor no meio, enquanto que áreas sob influência de grandes massas de vegetação, apresentaram características próprias, com microclimas diferentes das outras áreas da cidade, já que há uma contribuição na perda de energia para o meio e consequente queda de temperatura e aumento da umidade relativa do ar. Portanto, este estudo contribui para diagnosticar eventuais mudanças no clima urbano devido ao processo de crescimento de Cuiabá, que precisam ser considerados pelos planejadores e gestores para que sejam tomadas medidas que contribuam com a melhoria da qualidade ambiental e de vida da população.

Palavras-Chave: Ocupação do solo, vegetação, microclima.

\section{Abstract}

The urban characteristics associated with the types and degrees of density and use that cover the ground have the ability to change the climate elements that make up the local atmosphere. Therefore, this study aimed to analyze the influence of land use on the microclimate in Cuiaba-MT-Brazil through differences in temperature and humidity intraurbana the municipality. For this, we used the methodology of mobile nocturnal transects in four seasons, using a digital hygrometer, protected shelter, attached to the side of a vehicle that left the rural periphery, and the center has reached the opposite end of town, in the east / west and then north / south. Analysis was performed thermo-hygrometric and detection of climate anomalies such as heat island, showing the influence of anthropogenic changes in the urban environment. The urban density and vegetation removal are determining factors in behavior modification thermo-hygrometric, being evident the influence of the flow of vehicles in the heat gain in the middle, while areas under the influence of large masses of vegetation, showed characteristics with microclimates different from other areas of the city, since there is a contribution to the energy loss in the middle and fall in temperature and increase in relative humidity. Therefore, this study contributes to diagnose any changes in climate due to urban growth process of Cuiabá, which need to be considered by planners and managers to be taken to help with the improvement of environmental quality and life of the population.

Keywords: Land cover, vegetation, microclimate. 


\section{Introdução}

Os grandes aglomerados urbanos criam um verdadeiro clima urbano gerado através da interferência dos fatores que se processam sobre a camada de limite urbano e que agem alterando o clima em escala local, gerando uma atmosfera local com características climáticas próprias, ou seja, temperatura e umidade relativas do ar únicas, diferentes das verificadas nas áreas circunvizinhas. As características urbanas associadas aos tipos e níveis de adensamento e uso que recobrem o solo têm a capacidade de modificar os elementos climáticos que compõem a atmosfera local.

Criam-se anomalias na temperatura e na umidade, sendo a ilha de calor urbana (ICU) o fenômeno mais representativo dessas modificações contribuindoparaoarmazenamento de calor durante o dia na cidade, graças às propriedades térmicas e caloríficas dos materiais de construções e sua devolução para a atmosfera durante a noite.

Os principais condicionantes das modificações no clima urbano são: a produção do calor antropogênico (circulação de veículos e pessoas); a diminuição da evaporação decorrente da substituição da superfície original por concreto e asfalto e a canalização fechada de rios e córregos e a menor perda de calor sensível, devido à redução da velocidade do ar originada pelas edificações.

Cuiabá teve um crescimento populacional de aproximadamente $952 \%$ entre os anos de 1960 e 2010, conforme dados do IBGE (2010). Nas décadas de 70 e 80 o município passou por um processo de explosão populacional, sofrendo transformações na estrutura da paisagem e ocupação do solo urbano. Em algumas áreas houve uma concentração do crescimento vertical das edificações, entre as quais o centro da cidade. As construções verticalizadas absorvem e armazenam parte da energia calorífica durante o dia, emitindo-a durante a noite para o ar atmosférico, mantendo o ambiente aquecido por mais tempo.

Embora se admita a importância do clima no planejamento urbano, observa-se que pouco do conhecimento disponível da climatologia urbana é usado no planejamento das cidades. Desta forma, é necessário adentrar a cidade e identificar os aspectos dos diferentes dinamismos da vida urbana, como: tráfego de veículos automotores, remoção da cobertura vegetal, canalização de córregos, adensamento de construções, entre outros, na manutenção do equilíbrio ambiental.

\section{Objetivo}

O trabalho teve com objetivo a identificação das diferenças de temperatura e umidade intraurbana de Cuiabá- MT, em áreas com ocupações do solo diferenciadas, por meio de transectos móveis noturno.

\section{3. Área de estudo}

Este estudo foi desenvolvido no município de Cuiabá-Brasil, que está situado entre as coordenadas geográficas de 15010', 15050' de latitude sul e 50o50', 50010' de longitude oeste, na região central do Brasil. Possui uma área de $3.538,17 \mathrm{Km} 2$, correspondendo 254,57 Km2 à macrozona urbana e $3.283,60 \mathrm{Km} 2$ à área rural. Além do distrito-sede de Cuiabá, integram o município os distritos Coxipó da Ponte, Coxipó do Ouro e Guia (CUIABÁ, 2009).

O clima da cidade é do tipo Aw de Koppen, classificado como Tropical semi-úmido, com quatro a cinco meses secos (maio a setembro) e máximas diárias de temperatura que oscilam entre $30 \circ \mathrm{C}$ e $360 \mathrm{C}$, apresentando duas estações bem definidas, uma seca (outono-inverno) e uma chuvosa (primavera-verão).

Com clima Tropical Continental, sem influência marítima, onde já foi detectada a interferência do uso do solo urbano na ocorrência de ilhas de calor, Cuiabá apresenta baixa freqüência e velocidade média dos ventos, que torna a influência do espaço construído sobre a temperatura do ar mais perceptível, já que as trocas térmicas por convecção são minimizadas (OLIVEIRA, 2011).

\section{Método}

A metodologia para a coleta de temperatura e umidade consistiu na definição de dois transectos, com coletas móveis em pontos préestabelecidos com diferentes ocupações do solo, utilizando-se um termohigrômetro digital, protegido por abrigo, acoplado na lateral de um veículo que saiu da periferia (rural), passou pelo centro e chegou ao extremo oposto da cidade, em dois sentidos: leste/oeste - 1a (início) /1b (término) e norte/sul - 2a (início) /2b (término) (Figura 1). Apenas o ponto inicial do Transecto 2 (2a) encontra-se em área com características de área central, devido a proximidade do centro da cidade e do município vizinho - Várzea Grande.

Figura 1: Transecto 1a/1b - sentido Leste/Oeste e Transecto $2 a / 2 b$ - sentido Norte/Sul 
Figura 2: Transecto 1a/1b - sentido Leste/Oeste e Transecto $2 \mathrm{a} / 2 \mathrm{~b}$ - sentido Norte/Sul

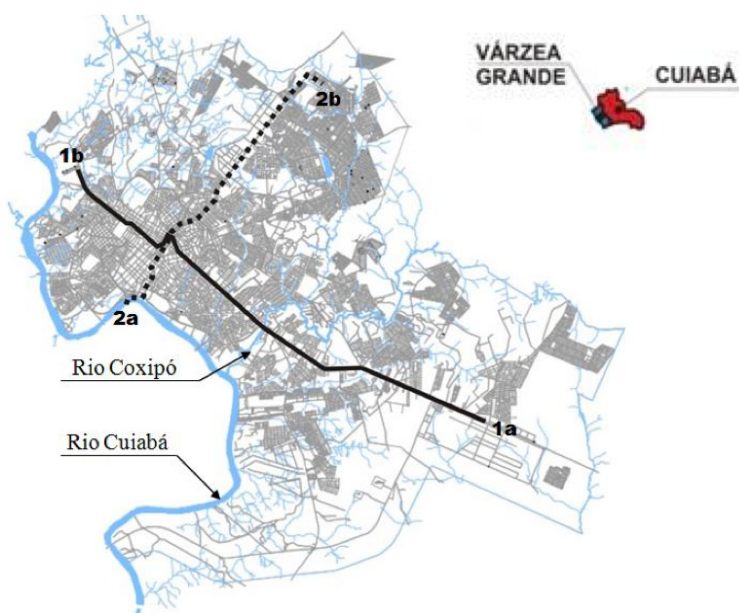

em diferentes períodos do ano de 2011 e parte de 2012. Foram estabelecidos dias com condições de tempo atmosférico ideal, ou seja, céu claro e ventos fracos (OKE,1982) em todas as estações do ano.

Utilizou-se um Datalogger de temperatura e umidade do ar da marca Instrutherm, modelo HT-500, protegido por abrigo, acoplado na lateral de um veículo, aproximadamente a $2,00 \mathrm{~m}$ do solo. A precisão do sensor de umidade é de $\pm 3 \%$ operando em intervalo de 0 a $100 \%$, e o sensor de temperatura tem precisão de1oC / 1,8oF (-4 a $122^{\circ} \mathrm{F} /-20$ a $50^{\circ} \mathrm{C}$ ) (Figura $2 \mathrm{a}$ ).

Simultaneamente, foi utilizado um GPS/MAP da marca Garmin, modelo 76Cx (Figura 2b), obtendo- se as coordenadas geográficas angular e UTM (Universal Transversa de Mercator), Zona 21, para precisão dos locais de medições dos pontos. Os instrumentos foram sincronizados em ciclo de medição de 10 segundos, ou seja, para cada dado de temperatura e umidade obteve-se a coordenada do ponto.

As medições foram feitas com velocidade do veículo entre 30 e $40 \mathrm{~km} / \mathrm{h}$, não ultrapassando uma hora em cada transecto, a partir das 20h, horário que as temperaturas não apresentam mudanças rápidas pela ausência da radiação solar, justamente pela diferença de tempo entre a primeira e a última medida.Além disso, é após o pôr do sol que a ICU atinge a intensidade máxima (OKE, 1982).

Primeiramente foi realizado o transecto no sentido leste/oeste $-1 \mathrm{a} / 1 \mathrm{~b}$ com 10 pontos fixos (Figura 3a) denominado Transecto $1 \mathrm{com}$ aproximadamente $19,6 \mathrm{~km}$, posteriormente, o transecto no sentido norte/sul - 2a/2b com 09 pontos fixos (Figura $3 \mathrm{~b}$ ) denominado Transecto 2 com aproximadamente $11,6 \mathrm{~km}$.
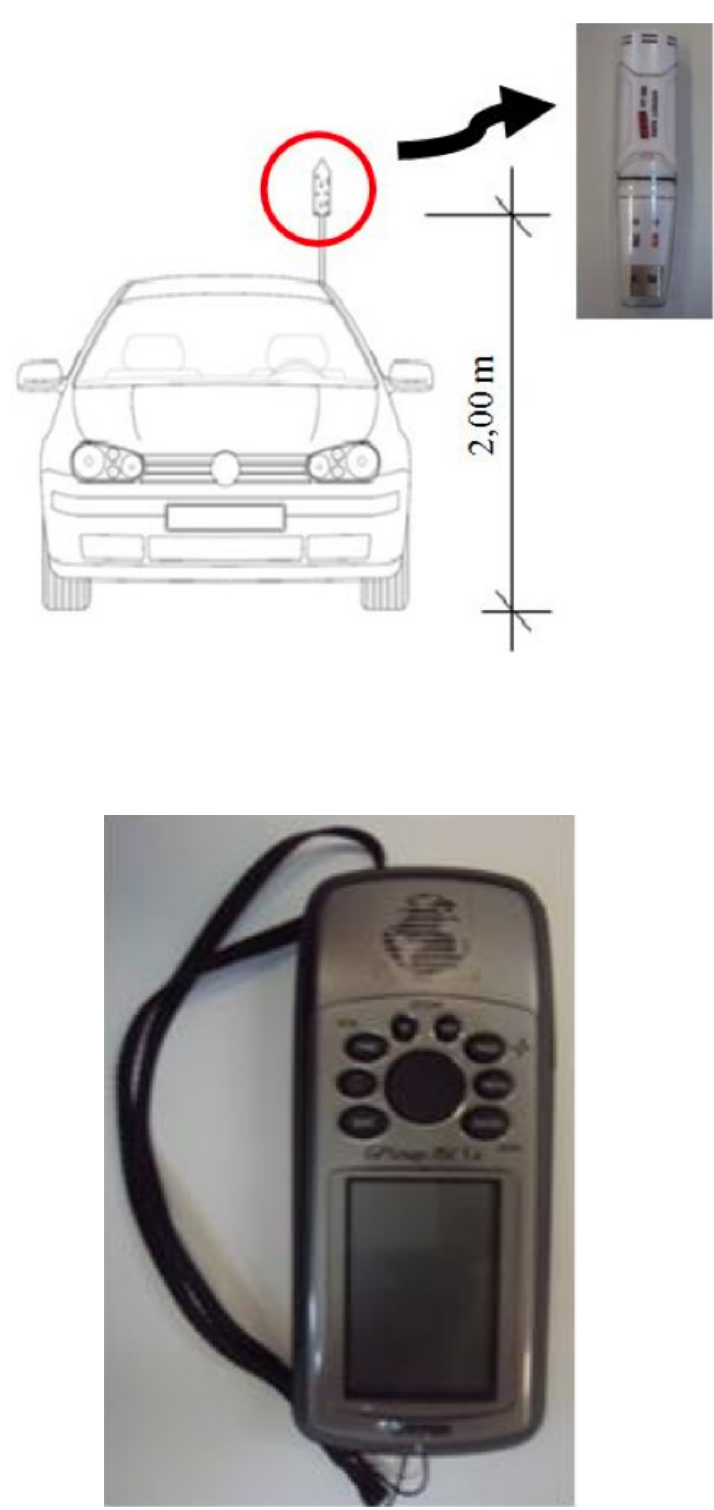

Figura 3: Pontos fixos de medição - sentido Leste/ Oeste - Transecto 1(a) e sentido Norte/Sul - Transecto 2 (b)

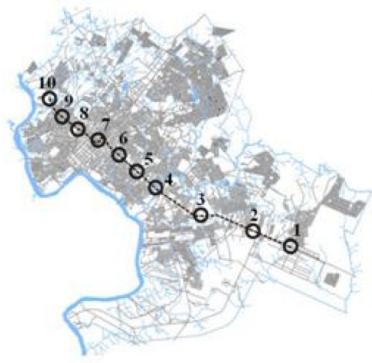

(a)

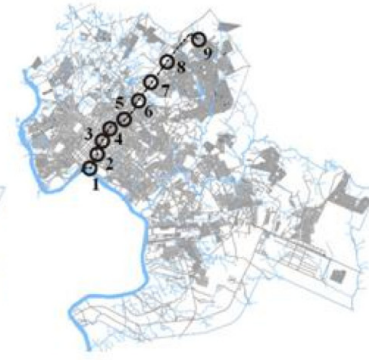

(b) 
Figura 4: Pontos fixos de medição - Transecto 1 e Transecto 2

TRANSECTO 1

1

2

3

4

5

6

7

8

9

10

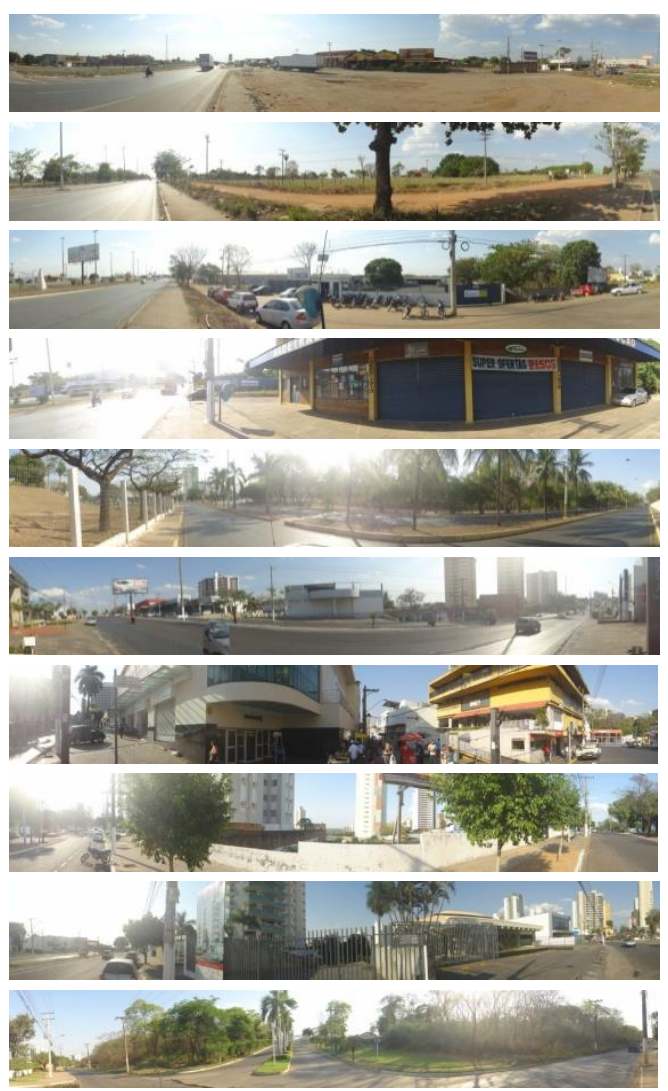

1

2

3

4

5

6

7

8

9

Parava-se com o carro em cada ponto por 1 minuto, obtendo-se 10 dados instantâneos do local, utilizando-se 8 dados, desconsiderandose os 2 primeiros para estabilização do aparelho.

Utilizou-se a técnica de agrupamentos hierárquicos - método de agrupamento comum (entre grupos) - Average Linkage Between Groups, para análise dos pontos fixos ao longo dos transectos, que se baseia na menor distância euclidiana entre dois pontos de uma matriz de similaridade, e no agrupamento por variância mínima, ou método de Ward. A análise de agrupamentos tem como objetivo maximizar as semelhanças entre os dados, criando grupos distintos, bem como diferenciar estes grupos entre si (LANDIM, 2003).

Os resultados da análise de agrupamento são apresentados na forma de diagramas hierárquicos (dendrogramas) horizontais, $\mathrm{O}$ dendrograma é lido de cima para baixo, nos quais as linhas verticais, ou o eixo y, representam os grupos unidos por ordem decrescente de semelhança, e a posição da reta, na escala ou o eixo $x$, indica as distâncias entre os grupos que foram formados. O número de classes ou grupos é determinado pela escolha de um nível de semelhança. Optou-se pelo corte no gráfico na
TRANSECTO 2
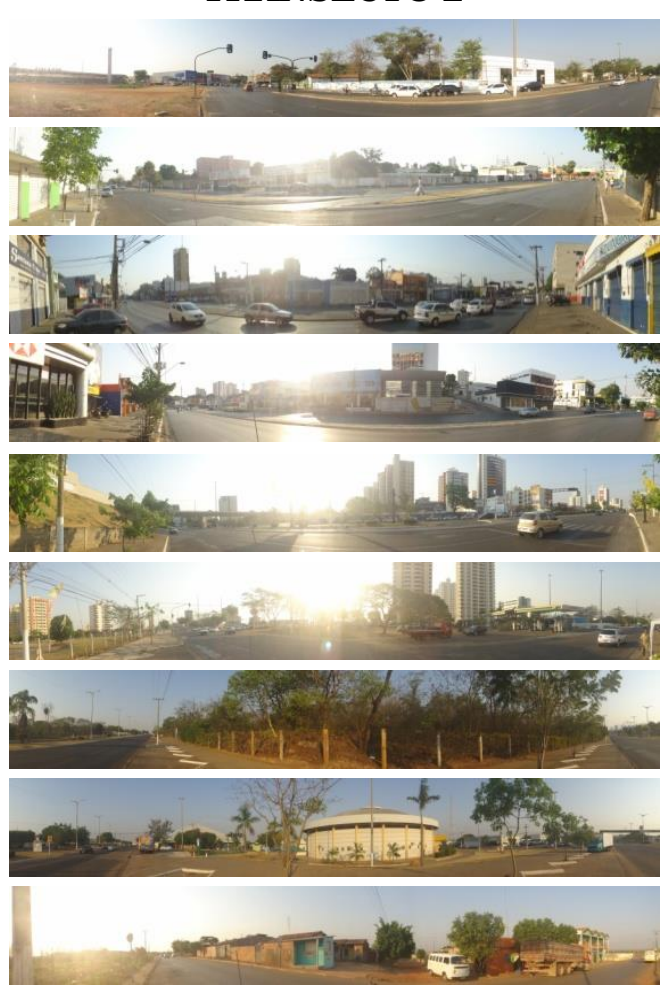

altura 5 para análise dos grupos homogêneos distintos.

Como forma de classificação dos pontos fixos, foi feito o cálculo da área verde em porcentagem em um raio de $200 \mathrm{~m}$ de influência em cada ponto, utilizou-se um software do tipo CAD (computer aided design - desenho auxiliado por computador) com auxílio das imagens no software Google Earth.

\section{Análise de resultados}

As condições climáticas intra-urbanas da cidade de Cuiabá-MT são avaliadas por meio dos gráficos temporo- espaciais de temperatura do ar e umidade relativa do ar ao longo dos transectos 1 e 2.

Observa-se as maiores temperaturas no Transecto 1 (Figura 5) entre os pontos 6 e 9 (P6T1 e P9T1, respectivamente) devido a influência de calor antropogênico proveniente principalmente do intenso fluxo de veículos automotores.

Segundo Callejas (2012) o fluxo de calor antropogênico dissipado dentro do dossel 
Figura 5: Distribuição da temperatura no Transecto 1

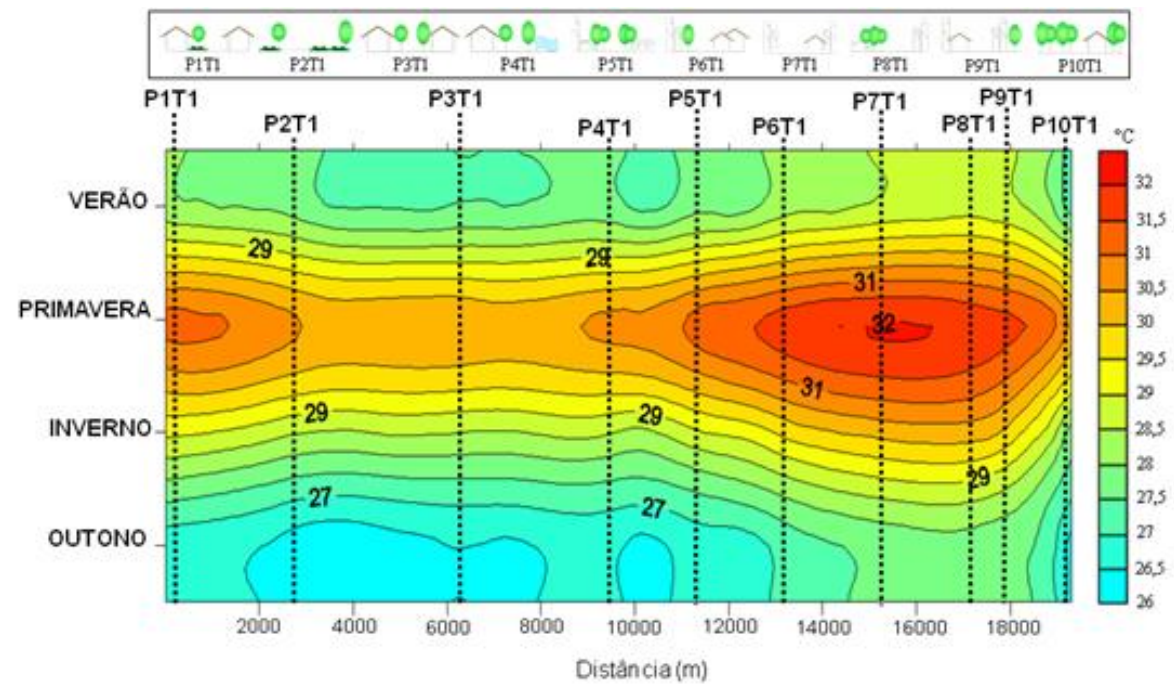

Figura 6: Distribuição da umidade no Transecto 1

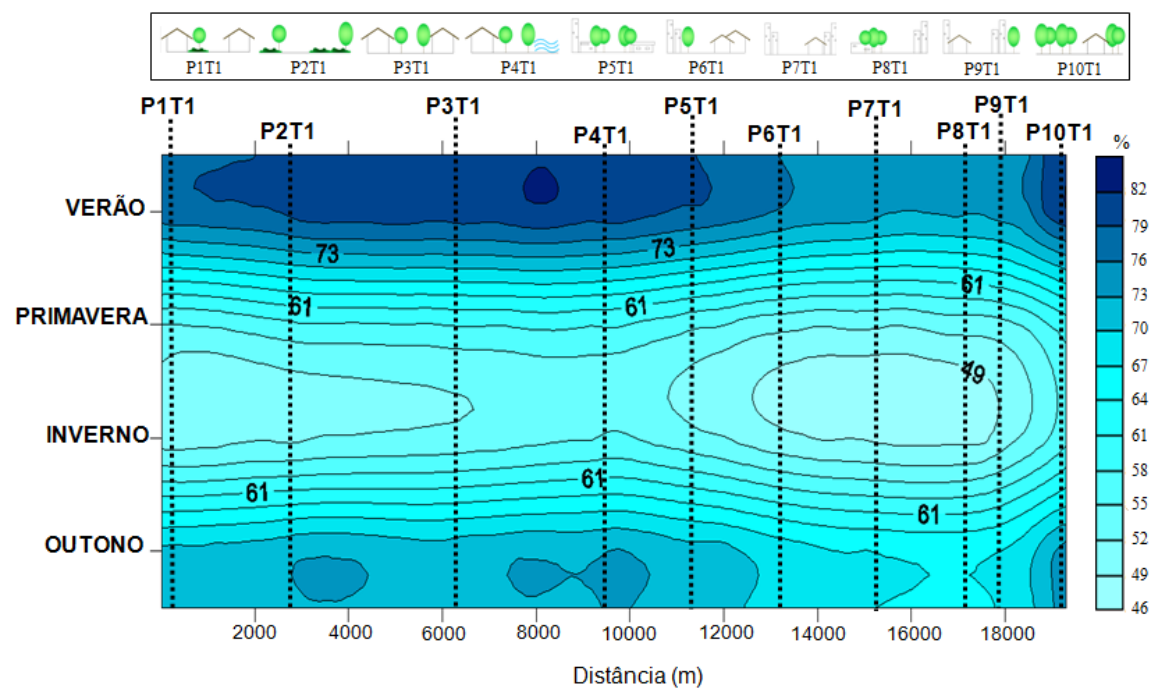

urbano pela ação antrópica chega a representar $33 \%$ da energia disponível no meio durante a noite, devido à supressão de radiação solar direta.

Devido a menor quantidade de superfícies ativas como áreas impermeabilizadas e canyons urbanos, entre os pontos 2 e 4 (P2T1 e P4T1, respectivamente), o fluxo de calor armazenado em ambientes com características de áreas periféricas é inferior ao do dossel urbano, fazendo com que a temperatura do ar seja minimizada nestas áreas.

Em média, as áreas entre P6T1 e P9T1 com as maiores mudanças por conta da urbanização inclusive com o centro comercial da cidade, apresentou um acréscimo de temperatura de $1,30^{\circ} \mathrm{C}$ em relação às áreas entre $\mathrm{P} 2 \mathrm{~T} 1$ e $\mathrm{P} 4 \mathrm{~T} 1$, ainda caracterizada com poucas modificações na ocupação do solo, configurando-se a formação de ilha de calor na cidade.

Fazendo-se uma análise quanto às estações do ano, a Primavera apresentou temperaturas mais rigorosas, característico do período na região, com média de $31,09^{\circ} \mathrm{C}$ e amplitude térmica de $1,78^{\circ} \mathrm{C}$,enquanto na estação do Outono, Inverno e Verão as médias foram de $26,87^{\circ} \mathrm{C}, 29,11^{\circ} \mathrm{C}$ e $27,95^{\circ} \mathrm{C}$, e a amplitude de $1,69^{\circ} \mathrm{C}, 2,64^{\circ} \mathrm{C}$ e $1,68^{\circ} \mathrm{C}$.

Analisando-se a umidade relativa ao longo do Transecto 1 (Figura 6), observou-se que as estações mais críticas são a do Inverno e Primavera com médias de $51,57 \%$ e $55,74 \%$, respectivamente, justificando as maiores amplitudes térmicas encontradas, já que a água é um eficiente regulador térmico.

A estação Verão apresentou a maior média de umidade relativa com $78,05 \%$, seguida do 
Figura 7: Distribuição da temperatura no Transecto 2

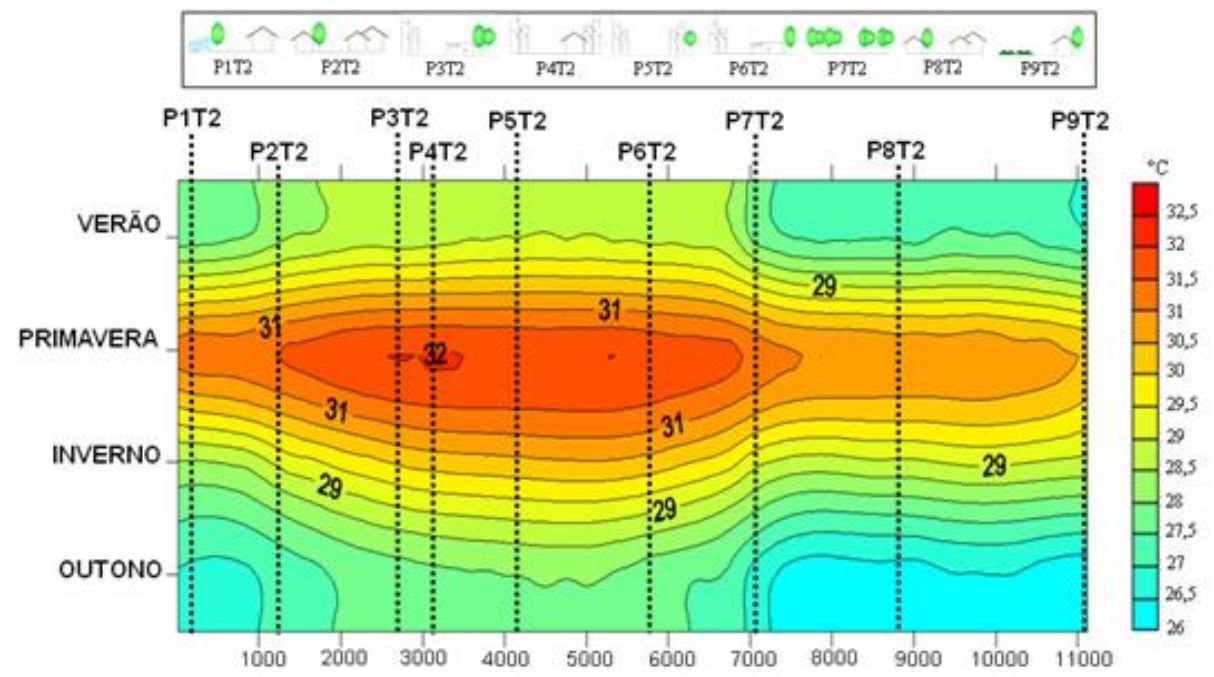

Figura 8: Distribuição da umidade no Transecto 2

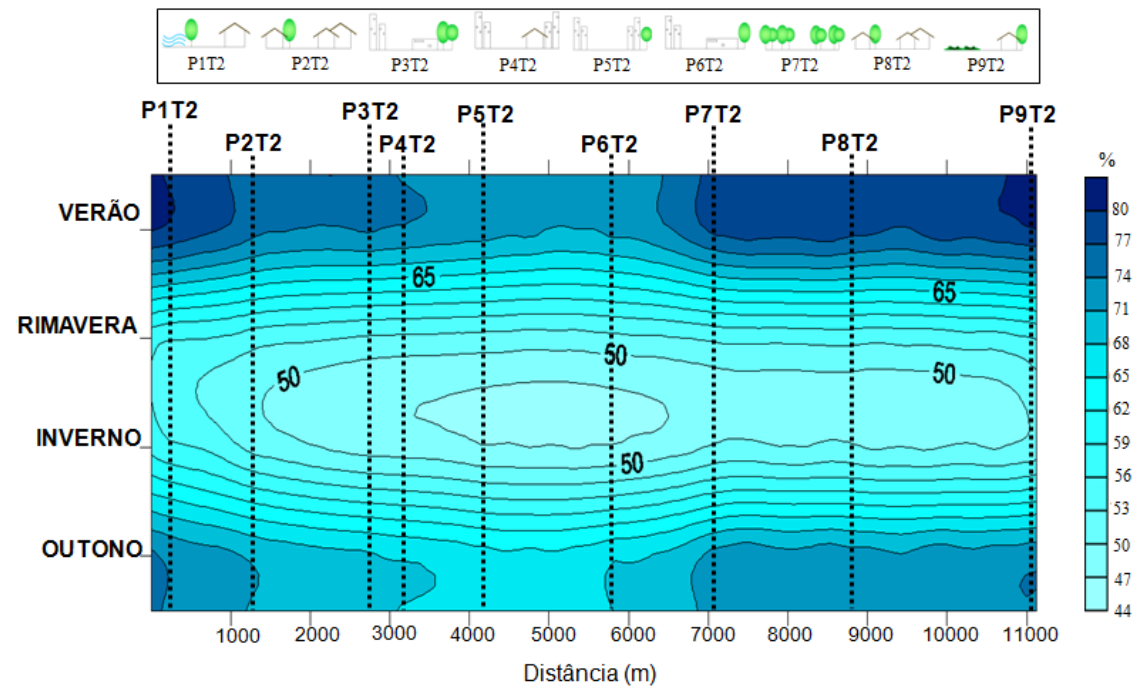

Outono com $70,42 \%$. Observa-se a mesma tendência no comportamento da umidade ao longo do transecto em todos os períodos analisados, com maior disponibilidade de umidade entre os pontos 2 e 5 (P2T1 e P5T1, respectivamente) por influência de áreas com características de zonas periféricas, sem canyons urbanos e vegetadas, responsável por elevar a disponibilidade de fluxo de calor latente no entorno imediato, além da influência da proximidade de cursos d'água como acontece no Ponto 4 (P4T1) as margens do Rio Coxipó.

Em média, as áreas entre P2T1 e P5T1 apresentaram um acréscimo de umidade relativa do ar de 5,38\% em relação às áreas entre P6T1 e P9T1, configurando-se a formação de ilha de umidade na cidade.

Quanto ao Transecto 2, observou-se que as maiores temperaturas foram verificadas entre os pontos 3 e 6 (P3T2 e P6T2, respectivamente) devido ao padrão de urbanização do local, com uso predominantemente comercial, com alta trafegabilidade de automóveis (Figura 7). A partir do ponto 7 (P7T2) localizado em frente a um parque urbano, as médias de temperatura diminuem, mantendo-se médias menores até o término do transecto devido a configuração urbana com padrão de área periférica com uso residencial e vazios urbano.

Constatou-se o mesmo comportamento térmico ao longo do ano em todo o transecto, apenas com médias de temperatura diferentes entre as estações, apresentando um acréscimo de temperatura de $1,35^{\circ} \mathrm{C}$ entre as áreas P3T2 e P6T2 em relação às áreas de P7T2 até P9T2.

Assim como no Transecto 1, a estação da Primavera apresentou a maior média de temperatura com $31,46^{\circ} \mathrm{C}$ com amplitude térmica de $1,55^{\circ} \mathrm{C}$, posteriormente a estação do Inverno com $29,40^{\circ} \mathrm{C}$ e amplitude de $2,03^{\circ} \mathrm{C}$, o Verão com $28,12^{\circ} \mathrm{C}$ e amplitude de $1,93^{\circ} \mathrm{C}$; e o Outono com $27,08^{\circ} \mathrm{C}$ e amplitude de $1,97^{\circ} \mathrm{C}$. 
Quanto a umidade relativa ao longo do Transecto 2 (Figura 8), observou-se que as estações mais secas são a do Inverno e Primavera, característico da região, com médias de 50,18\% e 53,58\%, respectivamente. Os maiores índices de umidade aconteceram nos pontos da extremidade do transecto, sendo o ponto inicial sob a influência do Rio Cuiabá e a outra extremidade sob a influência de massas de vegetação e lotes vazios.

Em média, as áreas entre P3T2 e P6T2 apresentaram um decréscimo de umidade relativa do ar de $3,81 \%$ em relação às áreas periféricas, evidenciando a influência da vegetação no aumento da umidade e comportando-se como amenizador de temperatura.

As análises estatísticas dos pontos fixos ao longo dos transectos, foram feitas por meio de dendrogramas da representação da similaridade dos locais utilizando o método de agrupamento comum (entre grupos) - Average Linkage Between Groups.

De acordo com o dendrograma do Transecto 1 (Figura 9), considerando-se a distância marcada no ponto 5 , pode-se observar a formação de 3 grandes grupos (Tabela 1).

Figura 9: Dendrograma do Transecto 1
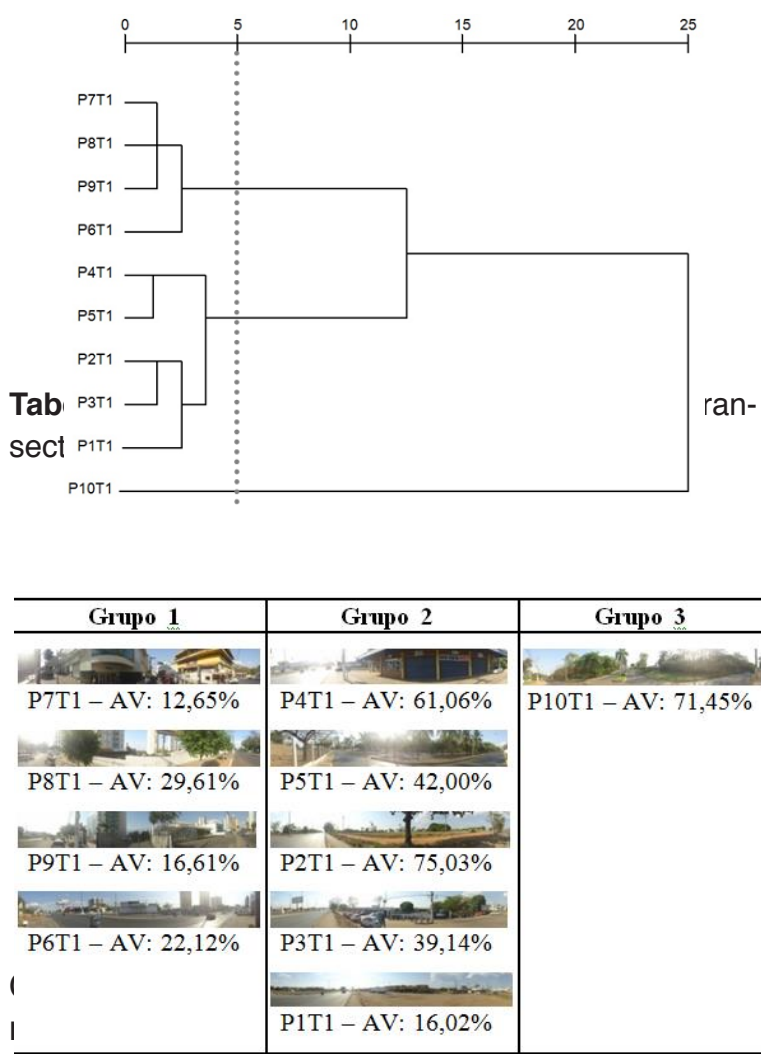

vegetação e corpos d'água, com canyons urbanos consolidados. São pontos com ocupação do solo predominantemente comercial e com grandes áreas impermeabilizadas, com as menores porcentagens de área verde (AV) entre os pontos.

O segundo grupo apresenta características semelhantes com pouca rugosidade superficial, mas com influência do tráfego de veículos. A presença de arborização também é característica entre os pontos, sendo que o Ponto 4 ainda sofre influência do Rio Coxipó, aumentando a umidade no entorno imediato, enquanto que o Ponto 5, que possui maior semelhança com o Ponto 4, a alta umidade é proveniente da grande área arborizada. Observou-se que o Ponto 1 apresentou porcentagem de área verde característico do grupo 1-16,02\%, evidenciandose que a menor quantidade de construções do entorno imediato influenciou as características climáticas locais.

O terceiro grupo é formado apenas pelo ponto 10 que está localizado próximo a um parque da cidade, apresentando como característica principal a maior quantidade de indivíduos arbóreos com porcentagem de área verde de $71,45 \%$. O local ainda apresenta pouco tráfego de veículos, diminuindo assim o calor antropogênico, e aumentando a influência da vegetação existente no ambiente.

De acordo com o dendrograma do Transecto 2 (Figura 10), considerando-se também a distância marcada no ponto 5 e utilizando o método de agrupamento comum (entre grupos) - Average Linkage Between Groups observou-se a formação de 4 grandes grupos (Tabela 2).

Figura 10: Dendrograma do Transecto 2

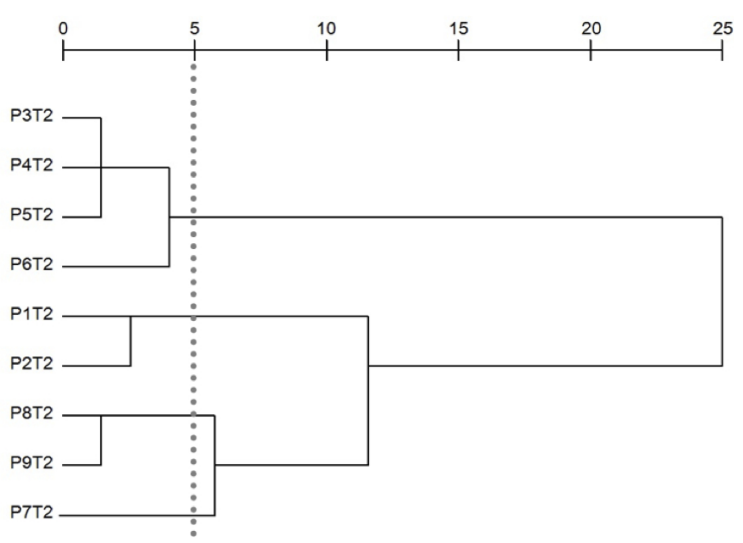

Tabela 2: Grupo da similaridade dos pontos no Transecto 2 AV: Área Verde 


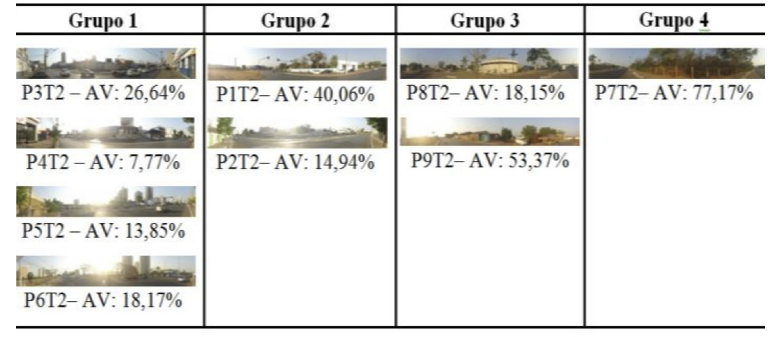

O primeiro grupo é formado pelos pontos localizados nas áreas mais urbanizadas do transecto, com fluxo de veículos intenso e grande impermeabilização do solo com as menores porcentagens de área verde (AV), além de possuir maior verticalização das edificações formando os canyons urbanos. Os pontos $3,4 \mathrm{e}$ 5 apresentam maiores semelhanças entre si, apresentando as mesmas características de ocupação do solo, sendo ponto 4 e 5 localizados nos cruzamentos de duas importantes vias de tráfego e o ponto 3 em área central da cidade. 0 ponto 6 , apresenta particularidades em relação ao grupo, pois está também localizado em uma área de intensa trafegabilidade, próximo a um shopping da cidade, mas a largura da via é maior em relação aos outros pontos, diminuindo desta forma, o efeito do canyon urbano.

O segundo grupo é formado pelos pontos 1 e 2 caracterizado pela baixa verticalização das edificações na proximidade, apesar de estarem localizados em áreas próximas ao centro da cidade, o fluxo de veículos neste locais, principalmente no horário de medição, é inferior aos do primeiro grupo. Sofrem influência da umidade proveniente do Rio Cuiabá, principalmente o ponto 1 devido a proximidade ao mesmo, enquanto que o ponto 2 apesar de estar mais distante e apresentar porcentagem de área verde característica do Grupo 1 $14,94 \%$, a configuração urbana entre os pontos facilita a influência da umidade, já que devido ao traçado da via e ausência de grandes obstáculos funcionando como corredores de vento com ar úmido.

No terceiro grupo estão os pontos 8 e 9 localizados em área periférica da cidade, sem influência de verticalização predial. Nestes pontos, a largura da rua diminui consideravelmente, sendo que no ponto 8 o fluxo de veículos e pessoas é maior devido a atrativos do entorno como um ginásio, quiosques de lanches rápidos, templos religiosos e maior ocupação do solo, além da menor quantidade de área verde comparando- se ao ponto 9. Este último está localizado em área de ocupação recente, com pouco fluxo de veículos e baixa circulação de pessoas, possui ainda grandes áreas vazias com vegetação rasteira.
O quarto grupo é formado pelo ponto 7 , que assim como o ponto 10 do Transecto 1 , está localizado próximo a um parque da cidade, sofrendo influência da massa de vegetação do local com porcentagem de área verde de $77,17 \%$. Nos horários iniciais e de término comercial ocorre um aumento no número de veículos trafegando na área, já que o local é corredor de tráfego do centro para bairros da periferia e vice/ versa.

\section{Conclusões}

$\mathrm{Na}$ análise microclimática ao longo do ano de pesquisa observou-se comportamentos climáticos característicos da região, com temperaturas altas, exceto em curtos períodos sob influência da "friagem", com a sazonalidade das chuvas em meses característicos, determinando desta forma, período úmido e seco.

A utilização de transectos móveis por meio de veículos automotores mostrou-se um método eficiente na investigação climatológica em todo o perímetro do município, admitindo estudos de áreas maiores, não restringindo estudos a bairros e/ou regiões, permitindo pesquisas em maiores escalas horizontais.

Os dados coletados nesta pesquisa evidenciaram que Cuiabá apresenta um perfil térmico que coincide com grande parte dos estudos realizados no período noturno, os quais registram na área mais densamente construída, um pico positivo de temperatura, comprovando-se a existência de ilha de calor na cidade.

Observa-se que em ambos os transectos, a estação do Inverno registrou média de temperatura do ar superior a estação do Verão que apresenta menor quantidade de energia armazenada no dossel urbano devido ao resfriamento proporcionada pela maior umidade.

Destaca-se que áreas sob influência de grandes massas de vegetação, apresentaram características próprias com microclima diferentes as outras áreas da cidade, contribuindo para formação de ilhas de umidade, já que há uma contribuição na perda de energia para o meio e consequente queda de temperatura e aumento da umidade relativa do ar, evidenciandose a importância da implantação de parques urbanos em locais de clima semelhantes ao de Cuiabá.

As mudanças provenientes da urbanização como uso de materiais impermeáveis, aumento 
da rugosidade da superfície por meio da verticalização das edificações formandos os canyons urbanos tem importante contribuição na energia disponível no meio ocasionando anomalias climáticas, sendo a principal delas a formação de ilhas de calor, evidenciada nos registros de maiores temperaturas nas áreas mais urbanizadas, centro comercial da cidade, em relação às áreas periféricas com características ainda rurais, em ambos os transectos.

A influência do fluxo de veículos automotores nos ganhos de calor no meio é evidente, já que áreas com menor circulação de automóveis apresentaram climas mais agradáveis às áreas com mesmas características de ocupação do solo, mas com menor fluxo de veículos, e consequentemente menor calor antropogênico. Portanto, o adensamento urbano e a supressão de vegetação são fatores determinantes na modificação do comportamento termohigrométrico, evidenciando-se a importância de estabelecer critérios de ocupação do solo, incentivando o uso de materiais que retenham menor quantidade de energia durante o dia e dissipem de forma mais acelerada durante a noite, de forma que as modificações no clima sejam amenizadas.

Deve-se ressaltar que este estudo irá contribuir no meio acadêmico e científico para diagnosticar eventuais mudanças no clima devido ao processo de crescimento de Cuiabá, que precisam ser considerados pelos planejadores e gestores para que sejam tomadas medidas que contribuam com a melhoria da qualidade ambiental e de vida da população.

\section{Agradecimentos}

Os autores agradecem à ELETROBRAS/ PROCEL e à CAPES pelos recursos financeiros aplicados no financiamento do projeto.

\section{Referências bibliográficas}

CALLEJAS, I. J. A. Avaliação temporal do balanço de energia em ambientes urbanos na cidade de Cuiabá-MT. Cuiabá. 265f. Tese (Doutorado), Programa de Pós-graduação em Física Ambiental, UFMT, Cuiabá, 2012.

CUIABÁ. (2009). Prefeitura Municipal de Cuiabá. Instituto de Pesquisa e Desenvolvimento Urbano. Perfil socioeconômico de Cuiabá. Vol.II - Cuiabá: IPDU/ Instituto de Planejamento e Desenvolvimento Urbano.
Instituto Brasileiro de Geografia e Estatística IBGE. Censo Demográfico (2010). Disponível em http://www.ibge.gov.br/ Acesso em 10/12/2011.

LANDIM, P. M. B. Análise Estatística de Dados Geológicos. 2 ed. Rio Claro: Edunesp. (2003).

OLIVEIRA, A. S. Influência da vegetação arbórea no microclima e uso de praças públicas. Cuiabá. 146f. Tese (Doutorado) -

Programa de Pósgraduação em Física Ambiental, UFMT, Cuiabá, 2011.

OKE, T. R. The energetic basis of the urban heat island. Quarterly Journal of the Royal Meteorological Society, v.108, n. 455, p. I-24, 1982. 